\title{
Current research status of cytomegalovirus infection after hematopoietic stem cell transplantation: a bibliometric analysis
}

\author{
Peng Chen ${ }^{1,2 \#}$, Zhenlan Du ${ }^{3,4,5 \#, \text { Shi Qiu }{ }^{6} \text {, Haitao Wang }}{ }^{1}$, Juan Zhang ${ }^{1}$, Daihong Liu ${ }^{1}$ \\ ${ }^{1}$ Senior Department of Hematology, The Fifth Medical Center of Chinese PLA General Hospital, Beijing, China; ${ }^{2}$ Chinese PLA Medical School, \\ Beijing, China; ${ }^{3}$ Department of Hematology and Oncology, Senior Department of Pediatrics, The Seventh Medical Center of Chinese PLA General \\ Hospital, Beijing, China; ${ }^{4}$ National Engineering Laboratory for birth defects prevention and control of key technology, Beijing, China; ${ }^{5}$ Beijing Key \\ Laboratory of Pediatric Organ Failure, Beijing, China; ${ }^{6}$ Department of Nutrition, The Seventh Medical Center of Chinese PLA General Hospital, \\ Beijing, China \\ Contributions: (I) Conception and design: P Chen, Z Du; (II) Administrative support: S Qiu; (III) Provision of study materials or patients: H Wang; (IV) \\ Collection and assembly of data: P Chen, J Zhang; (V) Data analysis and interpretation: P Chen, D Liu; (VI) Manuscript writing: All authors; (VII) \\ Final approval of manuscript: All authors. \\ \#These authors contributed equally to this work. \\ Correspondence to: Daihong Liu. Senior Department of Hematology, The Fifth Medical Center of Chinese PLA General Hospital, Beijing 100039, \\ China. Email: daihongrm@163.com.
}

Background Hematopoietic stem cell transplantation (HSCT) is an effective method for the treatment of hematological malignancies, severe aplastic anemia, and myelodysplastic syndromes. The most common infectious complication after HSCT is cytomegalovirus (CMV) infection. The purpose of this study was to analyze the status of research related to CMV infection after HSCT by conducting a literature search for CMV, hematopoietic, and stem cell transplantation.

Methods: The Science Citation Index Expanded (SCI-E) database in the Web of Science Core Collection (WOSCC) was used as the target database for our literature search. The subject search terms were CMV, hematopoietic, and stem cell transplantation, with the logical operation 'AND'. The search date range was from 1900 to June 15, 2021. We used CiteSpace software to analyze the literature. The analysis included: the annual change in the number of publications, the annual change in the number of references cited, the distribution of countries, the distribution of institutions, the distribution of journals, the distribution of authors, and the use of keywords.

Results: A total of 1,476 relevant documents were retrieved. The top 5 countries for number of publications were the United States, Germany, Japan, China, and Italy, while the top 5 countries for centrality scores were the United States, Australia, Germany, France, and Italy. The top 5 institutions for the number of publications were: Fred Hutchinson Cancer Research Center, the University of Washington, the University of Minnesota, Karolinska Institute, and Peking University. The top 4 institutions for centrality scores were: Fred Hutchinson Cancer Research Center, Henri-Mondor Hospital, the National Cancer Center, Karolinska University Hospital, and the University of Pavia. There were only 4 authors with a centrality score of 0.01 . The literature was mainly published in top hematology journals and journals for immunization and transplantation. The top 5 keywords used were: cytomegalovirus, bone marrow transplantation, recipient, infection, and versus host disease.

Conclusions: We found that CMV infection after HSCT has been attracting more and more attention by researchers, and that treatment has been the focus of current research.

Keywords: Hematopoietic stem cell transplantation (HSCT); cytomegalovirus (CMV); prevention; antiviral therapy; bibliometrics

Submitted Jun 30, 2021. Accepted for publication Sep 01, 2021.

doi: 10.21037/apm-21-2301

View this article at: https://dx.doi.org/10.21037/apm-21-2301 


\section{Introduction}

Hematopoietic stem cell transplantation (HSCT) is an effective method for the treatment of hematological malignancies, severe aplastic anemia, and myelodysplastic syndromes. Cytomegalovirus (CMV), a DNA virus from the herpesviridae family, has a serological positive rate of $30-97 \%$ and usually presents as a recessive infection in healthy people (1). CMV in the body of a recessively infected person is activated when the body's immune function declines, and the recessive infection can be transformed into a dominant infection. CMV infection is the most common infectious complication after HSCT, with an incidence of $30-70 \%$ (2). Clinical manifestations in patients include lung infection, inflammation of the stomach and intestines, encephalitis, hepatitis, retinitis, and asymptomatic CMV. Among them, CMV lung infection is the most serious, with a fatality rate of $>50 \%$ $(3,4)$. CMV infection can also affect the immune function of patients, increasing the risk of bacterial, fungal, and other pathogen infections, as well as graft versus host disease (GVHD), and bone marrow failure (5). In recent years, due to the preventive application of antiviral drugs to patients after HSCT, the incidence of CMV infection after transplantation has decreased, and the incidence of invasive $\mathrm{CMV}$ end-organ diseases has dropped from $30 \%$ to $5 \%$ (6). However, the occurrence of multidrug resistance and relapsed/refractory CMV infection still affects the prognosis of HSCT patients and is an urgent problem in need of solutions (7).

Bibliometrics, which is a method for analyzing existing documents, has been gradually developing in recent years. This method is aimed at a particular problem within a specific field and involves searching relevant databases to find documents. By analyzing these documents, we can understand the current research focus. The research overview of an issue can be described in terms of the annual publication status and citation status of the literature, the countries, institutions, and researchers conducting the research, the journals that publish the literature, and the keywords used. A general understanding of the research trends in a given field has important reference value for researchers $(8,9)$. The purpose of this study was to analyze the status of research related to CMV infection after HSCT by conducting a literature search for CMV, hematopoietic, and stem cell transplantation.

\section{Methods}

\section{Database}

We used the Science Citation Index Expanded (SCI-E) database in the Web of Science Core Collection (WOSCC) as the target database for our literature search. The SCI-E database, founded and published by the Institute for Scientific Information, is a citation database of scientific and technological papers from more than 170 scientific disciplines. It contains more than 8,000 major journals, along with their citation information. As an important component of the core collection of Web of Science, SCI-E is a citation retrieval tool and also an important basis for metrological research and scientific research evaluation.

\section{Retrieval method}

We used subject term retrieval, which is a common retrieval method used in bibliometrics. The subject terms were cytomegalovirus, hematopoietic, and stem cell transplantation, with the logical operation 'AND'. There was no restriction on the publication date, which ranged from 1900 to the final search date for this study on June 15, 2021.

\section{Analysis method}

All search result records and cited references were exported in plain text format. We then used CiteSpace software to analyze the exported files. The analysis included annual change in the amount of literature published, annual change in the amount of literature cited, distribution of the source countries, distribution of the source institutions, distribution of journals, distribution of authors, and the use of keywords. The results of the analysis included the number of documents; the differences between the source countries, institutions, and author relationships; and the frequency of keyword use and the relationships between them.

\section{Statistical processing}

As a descriptive study mainly using quantity and percentages to indicate the status of the literature, we did not use grouping or comparison between groups, or set a $\mathrm{P}$ value. 
Table 1 Document type analysis

\begin{tabular}{lcc}
\hline Document type & Record count & \% of 1,476 \\
\hline Articles & 1161 & 78.66 \\
Review articles & 198 & 13.41 \\
Meeting abstracts & 81 & 5.49 \\
Proceedings papers & 29 & 1.96 \\
Letters & 21 & 1.42 \\
Early access & 15 & 1.02 \\
Editorial materials & 11 & 0.75 \\
Book chapters & 3 & 0.20 \\
Reprints & 3 & 0.20 \\
Notes & 1 & 0.07 \\
\hline
\end{tabular}

\section{Results}

\section{Document types}

We retrieved 1,523 records, of which 47 were recategorized, leaving a total of 1,476 documents for inclusion in our study (Tables 1,2, Figure 1). The citation frequency of these documents totaled 38,784 , the average number of citations per document was 26.28 , and the h-index was 88 (Figure 2). Among the 1,476 records, there were 1,161 original articles, 198 reviews, 81 meeting abstracts, 29 proceedings papers, 21 letters, 15 early access, 11 editorial materials, 3 book chapters, 3 reprints, and 1 note. The results showed that research literature on CMV infection after HSCT is roughly increasing year by year, with the number of documents in 2020 greatly increasing. The number of references cited showed a more obvious increasing trend. These results showed that research in this field is currently receiving more and more attention.

\section{Distribution of countries and institutions}

We used CiteSpace V software to analyze and generate a national visualization map of document sources (Figure 3). The figure shows that relevant documents came from 83 countries and regions, with 484 connections between them. Similarly, the institutions visualization map (Figure 4) shows that a total of 594 institutions have participated in the research of this field, and there are 613 contacts between institutions. The top 5 countries for number of publications were: the United States, Germany, Japan, China, and Italy; and the top 5 countries for centrality score were the
Table 2 Annual distribution of the number of documents

\begin{tabular}{|c|c|c|}
\hline Year & Record count & $\%$ of 1,476 \\
\hline 2021 & 51 & 3.46 \\
\hline 2020 & 156 & 10.57 \\
\hline 2019 & 114 & 7.72 \\
\hline 2018 & 116 & 7.86 \\
\hline 2017 & 113 & 7.66 \\
\hline 2016 & 90 & 6.10 \\
\hline 2015 & 74 & 5.01 \\
\hline 2014 & 95 & 6.44 \\
\hline 2013 & 75 & 5.08 \\
\hline 2012 & 65 & 4.40 \\
\hline 2011 & 54 & 3.66 \\
\hline 2010 & 58 & 3.93 \\
\hline 2009 & 55 & 3.73 \\
\hline 2008 & 58 & 3.93 \\
\hline 2007 & 43 & 2.91 \\
\hline 2006 & 46 & 3.12 \\
\hline 2005 & 31 & 2.10 \\
\hline 2004 & 30 & 2.03 \\
\hline 2003 & 37 & 2.51 \\
\hline 2002 & 32 & 2.17 \\
\hline 2001 & 25 & 1.69 \\
\hline 2000 & 16 & 1.08 \\
\hline 1999 & 4 & 0.27 \\
\hline 1998 & 11 & 0.75 \\
\hline 1997 & 8 & 0.54 \\
\hline 1996 & 7 & 0.47 \\
\hline 1995 & 2 & 0.14 \\
\hline 1994 & 3 & 0.20 \\
\hline 1993 & 2 & 0.14 \\
\hline 1992 & 2 & 0.14 \\
\hline 1991 & 2 & 0.14 \\
\hline 1990 & 1 & 0.07 \\
\hline
\end{tabular}

United States, Australia, Germany, France, and Italy. These countries had more relevant research results and also more cooperation (Tables 3,4). In terms of research institutions, 


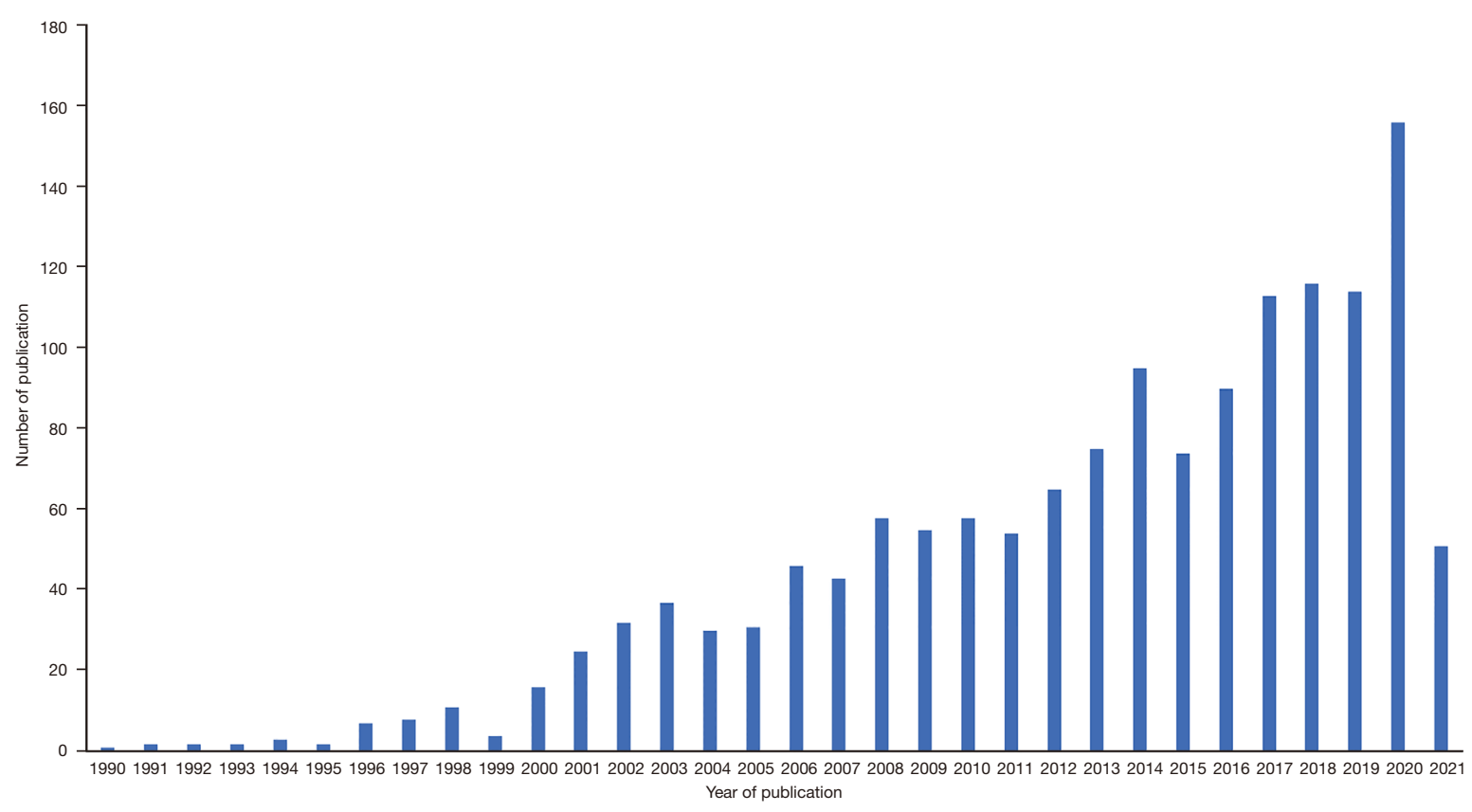

Figure 1 Annual change in the number of publications.

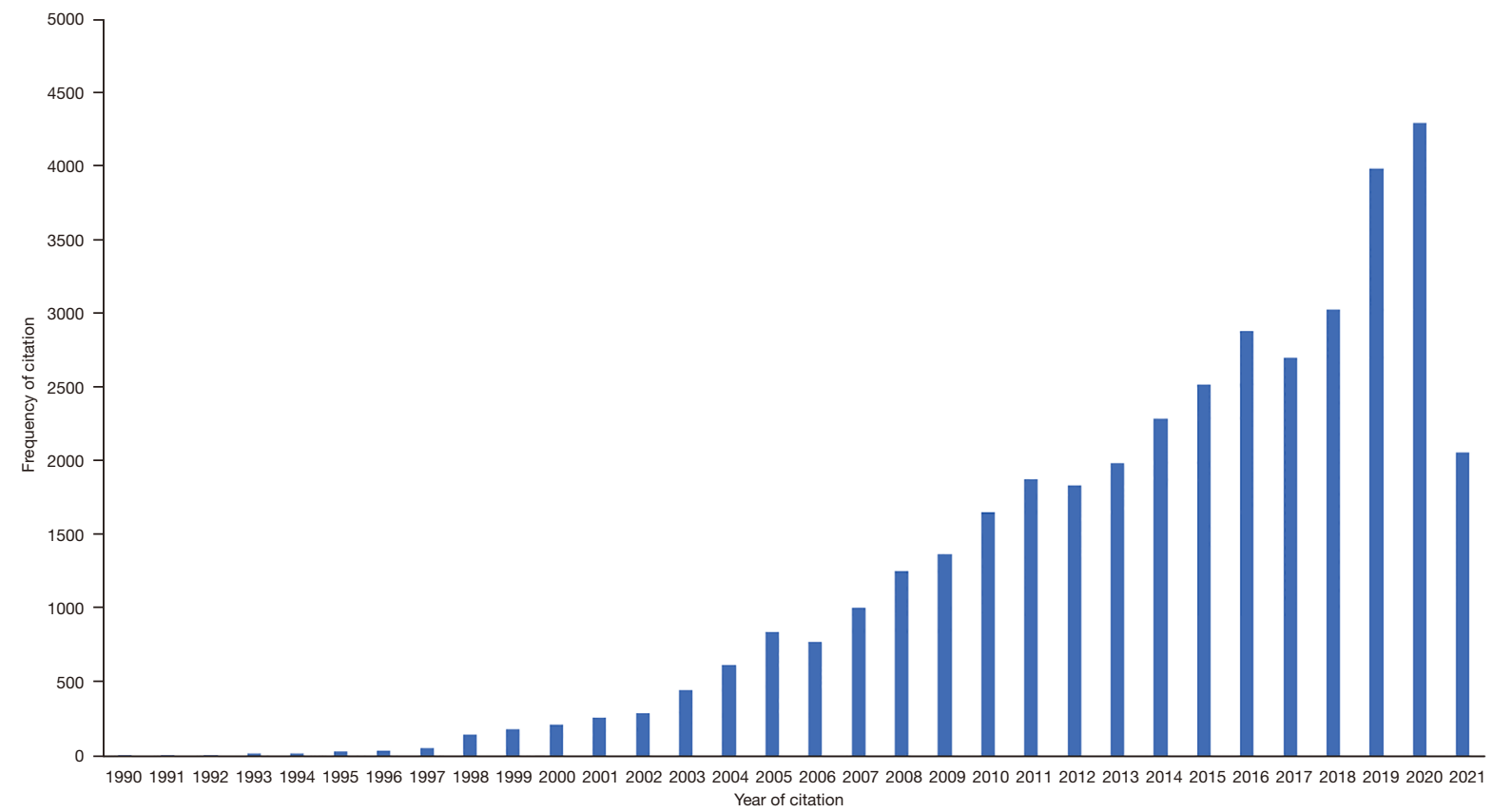

Figure 2 Annual trends in the frequency of publication citations. 


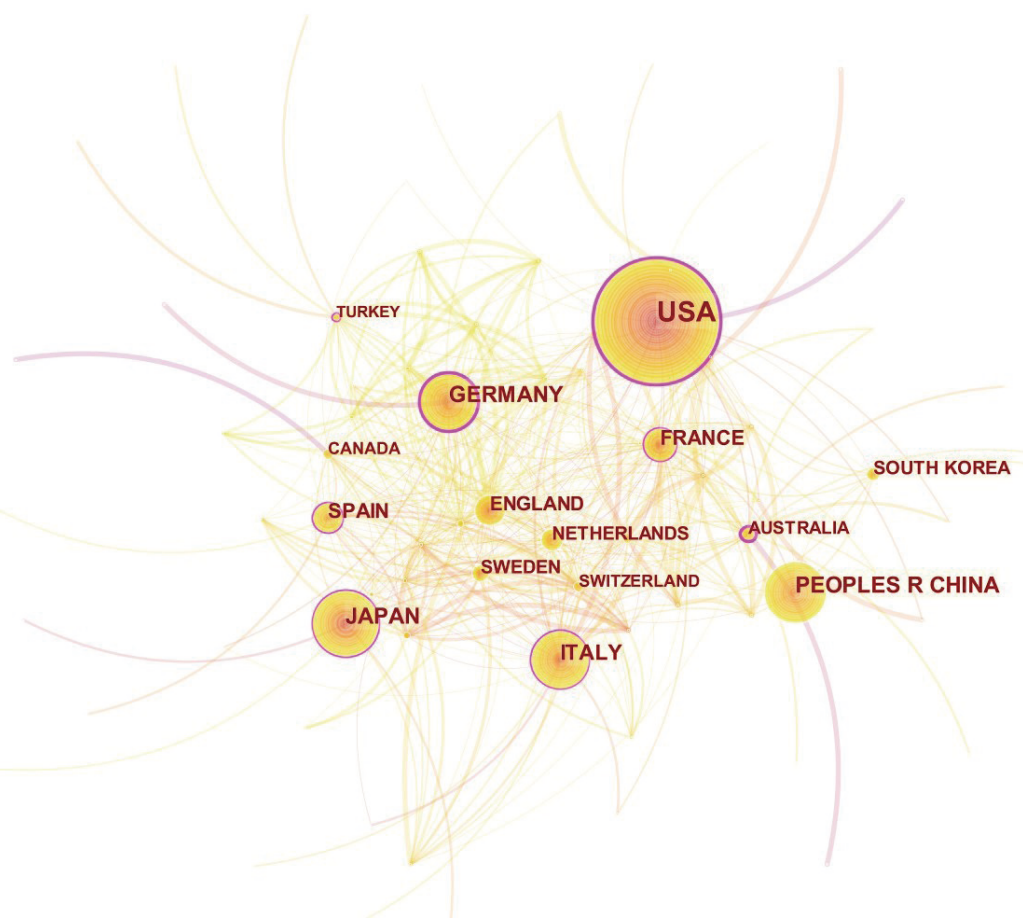

Figure 3 Visualization map of countries.

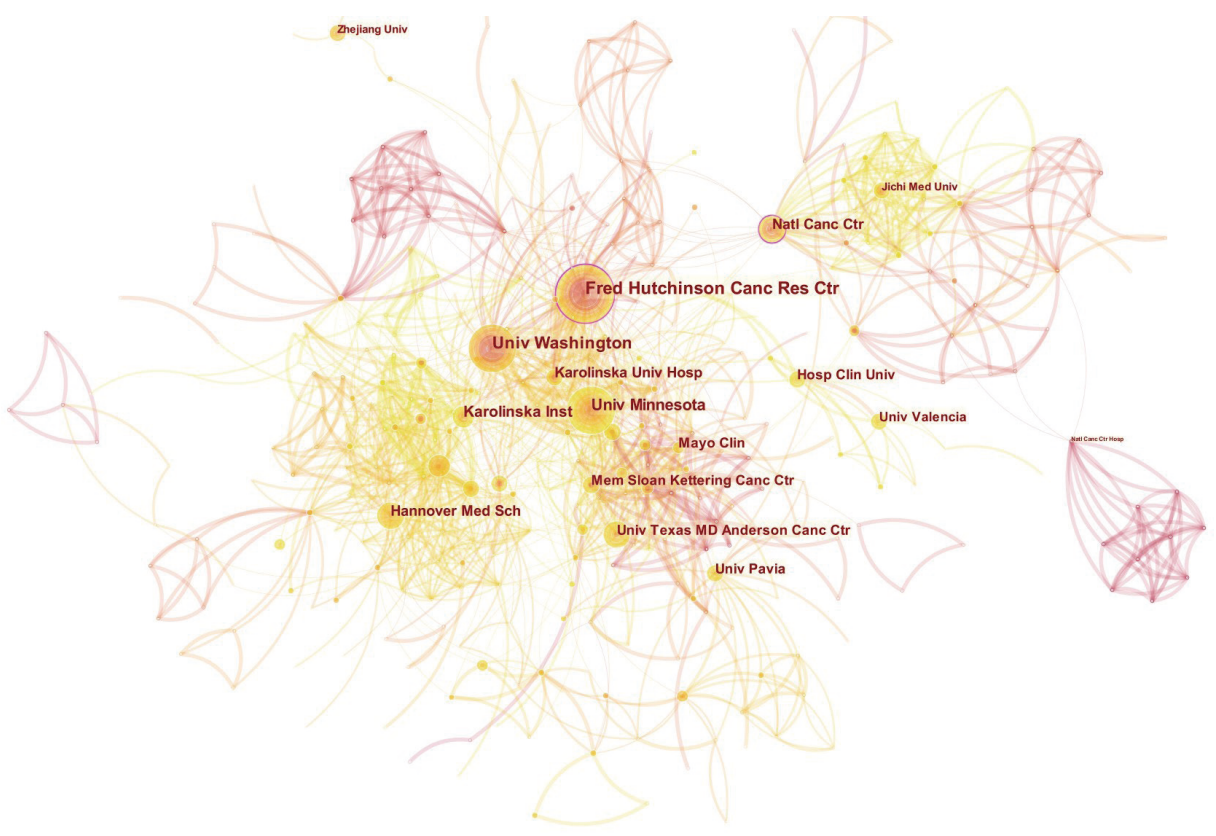

Figure 4 Visualization map of institutions. 
Table 3 Top 10 countries in terms of publications

\begin{tabular}{lcc}
\hline Rank & Country & Records \\
\hline 1 & USA & 461 \\
2 & Germany & 153 \\
3 & Japan & 147 \\
4 & China & 138 \\
5 & Italy & 131 \\
6 & France & 85 \\
7 & Spain & 81 \\
8 & England & 72 \\
9 & Netherlands & 58 \\
10 & South Korea & 55 \\
\hline
\end{tabular}

Table 4 Top 10 countries for centrality

\begin{tabular}{lcc}
\hline Rank & Country & Centrality \\
\hline 1 & USA & 0.32 \\
2 & Australia & 0.27 \\
3 & Germany & 0.22 \\
4 & France & 0.18 \\
5 & Italy & 0.18 \\
6 & Japan & 0.14 \\
7 & Turkey & 0.14 \\
8 & Spain & 0.11 \\
9 & Canada & 0.08 \\
10 & England & 0.08 \\
\hline
\end{tabular}

Table 5 Top 10 institutions for number of publications

\begin{tabular}{llc}
\hline Rank & Institution & Records \\
\hline 1 & Fred Hutchinson Canc Res Ctr & 56 \\
2 & Univ Washington & 53 \\
3 & Univ Minnesota & 38 \\
4 & Karolinska Inst & 33 \\
5 & Peking Univ & 27 \\
6 & Natl Canc Ctr & 26 \\
7 & Karolinska Univ Hosp & 26 \\
8 & Hannover Med Sch & 26 \\
9 & Mayo Clin & 23 \\
10 & Hosp Clin Univ & 23 \\
\hline
\end{tabular}

Table 6 Top 10 institutions by centrality

\begin{tabular}{lcc}
\hline Rank & Institution & Centrality \\
\hline 1 & Fred Hutchinson Canc Res Ctr & 0.20 \\
2 & Hop Henri Mondor & 0.18 \\
3 & Natl Canc Ctr & 0.13 \\
4 & Karolinska Univ Hosp & 0.09 \\
5 & Univ Pavia & 0.07 \\
6 & Mem Sloan Kettering Canc Ctr & 0.07 \\
7 & Univ Hosp & 0.07 \\
8 & Duke Univ & 0.07 \\
9 & Weill Cornell Med Coll & 0.07 \\
10 & Univ Washington & 0.06 \\
\hline
\end{tabular}

the top 5 were: Fred Hutchinson Cancer Research Center, the University of Washington, the University of Minnesota, Karolinska Institute, and Peking University. The top 4 institutions for centrality score were: Fred Hutchinson Cancer Research Center, Henri-Mondor Hospital, the National Cancer Centre, Karolinska University Hospital, and the University of Pavia. The results showed that Fred Hutchinson Cancer Research Center had the most research results and also the most cooperation (Tables 5,6). There were many authors who have published more than 10 articles, but only 4 had a centrality score of 0.01 , indicating that there was relatively little cooperation between authors (Figure 5, Tables 7,8). However, there were more mutual citations among authors. Among them, P. Ljungman and M. Boeckh were cited more frequently than other authors. Further analysis showed that most documents by these 2 authors were published in top hematology journals or top comprehensive medical journals, such as Blood and the New England Journal of Medicine (Figure 6, Tables 9,10).

\section{Analysis of journal distribution}

The results showed that the 1,476 documents were from 374 journals, among which 26 journals published more than 10 articles (Table 11). These 26 journals published a total of 833 related articles, accounting for $56.44 \%$ of the total literature (Table 11). The results showed that research in this field is mainly published in the top hematology journals and journals for immunity and transplantation. In terms of publication citations, hematology journals were cited more frequently, along with several top comprehensive medical 


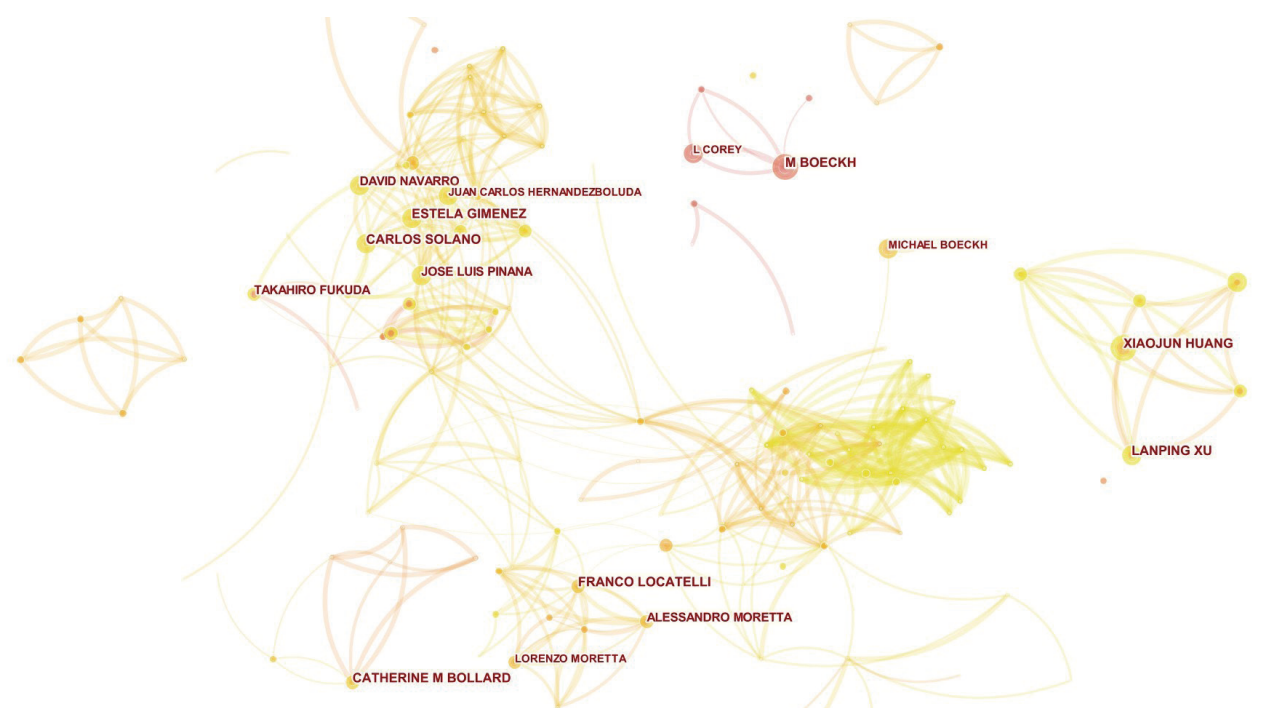

Figure 5 Visualization map of coauthors.

Table 7 Top 10 authors for number of articles published

\begin{tabular}{lcc}
\hline Rank & Author & Records \\
\hline 1 & Boeckh M & 18 \\
2 & Huang XJ & 16 \\
3 & Locatelli F & 16 \\
4 & Xu LP & 15 \\
5 & Solano C & 15 \\
6 & Gimenez E & 15 \\
7 & Navarro D & 14 \\
8 & Fukuda T & 13 \\
9 & Bollard CM & 13 \\
10 & Pinana JL & 13 \\
\hline
\end{tabular}

Table 8 Top 10 authors by centrality

\begin{tabular}{lcc}
\hline Rank & Author & Centrality \\
\hline 1 & Fukuda T & 0.01 \\
1 & Oshima K & 0.01 \\
1 & Ganser A & 0.01 \\
1 & Wolff D & 0.01 \\
\hline
\end{tabular}

journals (Tables 12,13).

\section{Keyword analysis}

CiteSpace V software was used to generate a keyword cooccurrence map. A total of 337 keywords were used in the documents, and there were 3,036 links between keywords (Figure 7). The top 5 most frequently used keywords were: cytomegalovirus, bone marrow transplantation, recipient, infection, and versus host disease; the top 5 keywords for centrality score were: bone marrow transplantation, hematopoietic stem cell, transplantation, cytomegalovirus, and versus host disease (Tables 14,15). We then used CiteSpace to perform burst detection on frequently used keywords (Figure 8). The results showed that in recent years, the keywords used in this field mainly involved treatment.

\section{Discussion}

This study analyzed the status of literature related to CMV infection after HSCT. The results showed that the amount of literature in this field is roughly increasing year by year. Related research and cooperation mainly came from 


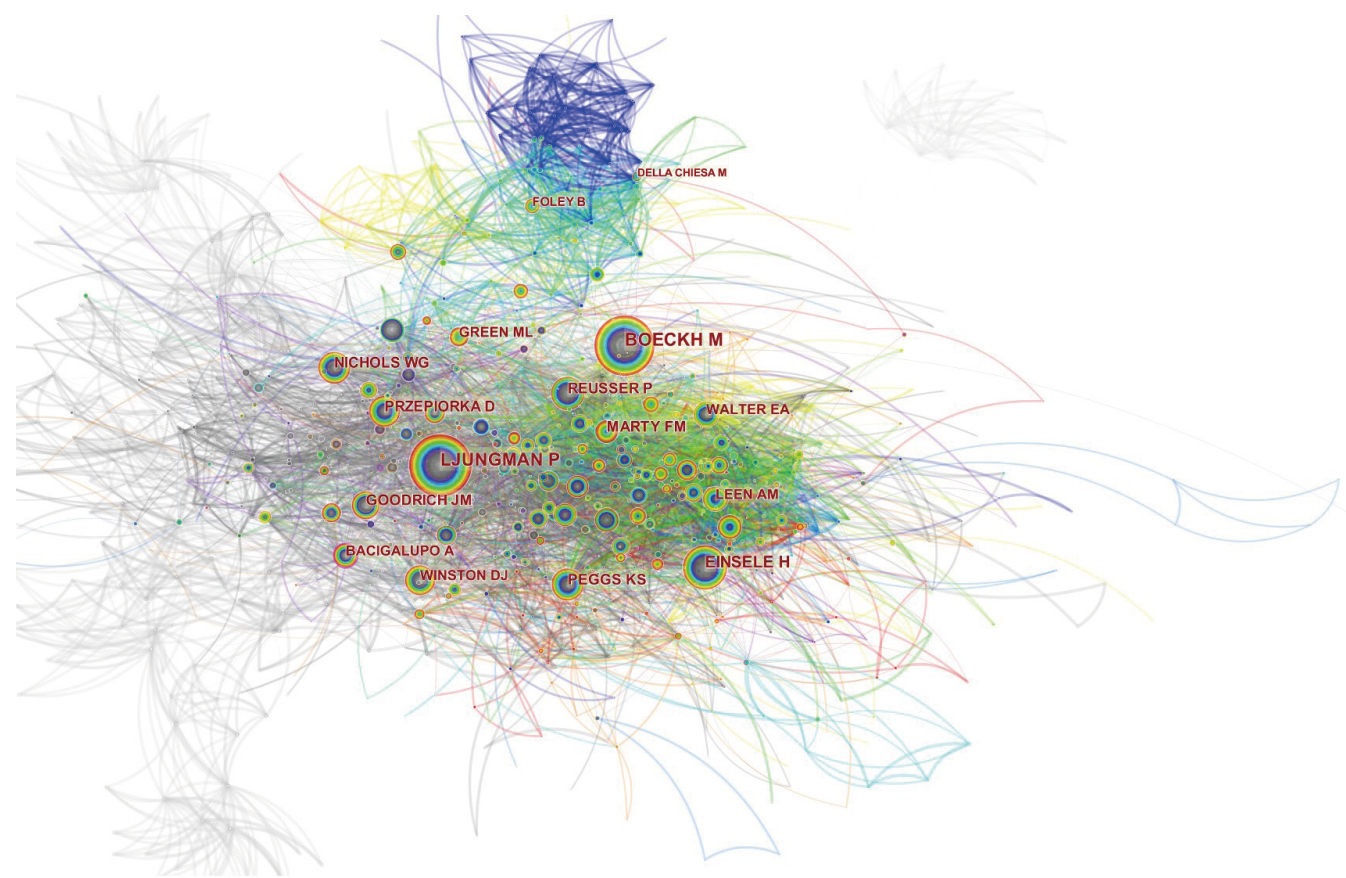

Figure 6 Visualization map of author co-citations.

Table 9 Top 10 co-cited authors

\begin{tabular}{lcc}
\hline Rank & Author & Records \\
\hline 1 & Ljungman P & 513 \\
2 & Boeckh M & 483 \\
3 & Einsele H & 245 \\
4 & Peggs KS & 159 \\
5 & Marty FM & 158 \\
6 & Nichols WG & 154 \\
7 & Reusser P & 152 \\
8 & Przepiorka D & 142 \\
9 & Goodrich JM & 130 \\
10 & Winston DJ & 127 \\
\hline
\end{tabular}

developed countries such as the United States, Germany, and Italy. Fred Hutchinson Cancer Research Center published the largest number of documents and also had the most collaborations. However, the results of author analysis showed that there was relatively little collaboration between authors in this field. Top hematology journals and comprehensive medical journals were the most relevant journals for this field. Keyword hotspot analysis showed
Table 10 Top 10 cited authors by centrality

\begin{tabular}{lcc}
\hline Rank & Author & Centrality \\
\hline 1 & Goodrich JM & 0.13 \\
2 & Einsele H & 0.12 \\
3 & Bacigalupo A & 0.12 \\
4 & Peggs KS & 0.10 \\
5 & Meyers JD & 0.10 \\
6 & Nichols WG & 0.08 \\
7 & Ljungman P & 0.07 \\
8 & Reusser P & 0.07 \\
9 & Apperley JF & 0.07 \\
10 & Boeckh M & 0.06 \\
\hline
\end{tabular}

that the focus of research in recent years has been on the treatment of CMV infection after HSCT.

Since most people carry CMV in their bodies, CMV infection is prone to occur when the body's immunity is weakened or suppressed (1). However, it has also been found that not every patient receiving HSCT develops CMV infection or shows obvious clinical symptoms (2). Therefore, analysis of the risk factors for CMV infection 
Table 11 Top 26 journals by article volume

\begin{tabular}{|c|c|c|}
\hline Publication title & Record count & $\%$ of 1,476 \\
\hline $\begin{array}{l}\text { Biology of Blood and Marrow } \\
\text { Transplantation }\end{array}$ & 203 & 13.75 \\
\hline Bone Marrow Transplantation & 103 & 6.98 \\
\hline Blood & 98 & 6.64 \\
\hline Transplant Infectious Disease & 80 & 5.42 \\
\hline Frontiers In Immunology & 38 & 2.58 \\
\hline Clinical Infectious Diseases & 24 & 1.63 \\
\hline Annals of Hematology & 22 & 1.49 \\
\hline Cytotherapy & 19 & 1.29 \\
\hline International Journal of Hematology & 19 & 1.29 \\
\hline Transplantation & 19 & 1.29 \\
\hline Haematologica & 16 & 1.08 \\
\hline Journal Of Clinical Virology & 16 & 1.08 \\
\hline Journal Of Medical Virology & 15 & 1.02 \\
\hline Plos One & 15 & 1.02 \\
\hline Blood Advances & 14 & 0.95 \\
\hline European Journal of Haematology & 14 & 0.95 \\
\hline Journal of Infectious Diseases & 14 & 0.95 \\
\hline Experimental Hematology & 13 & 0.88 \\
\hline Pediatric Blood Cancer & 13 & 0.88 \\
\hline Pediatric Transplantation & 13 & 0.88 \\
\hline Clinical Transplantation & 12 & 0.81 \\
\hline Journal of Clinical Microbiology & 12 & 0.81 \\
\hline Transplantation Proceedings & 11 & 0.75 \\
\hline American Journal of Transplantation & 10 & 0.68 \\
\hline Transfusion & 10 & 0.68 \\
\hline Transplantation and Cellular Therapy & 10 & 0.68 \\
\hline
\end{tabular}

after HSCT has been thoroughly researched. Research results have shown that the main risk factors include: (I) recipient serum $C M V$ antibody positive ( $\mathrm{OR}=8.0$ ), (II) donor serum CMV antibody negative/recipient antibody positive ( $\mathrm{OR}=1.2)$, (III) acute graft-versus-host disease after surgery $(\mathrm{OR}=3.2$ ), (IV) unrelated donors or relative donors whose human leukocyte antigens do not match $(\mathrm{OR}=1.6)$, and $(\mathrm{V})$ anti-CMV drugs were not given preventively after transplantation $(10,11)$. Other risk factors include the use of antihuman thymocyte immunoglobulin, glucocorticoid
Table 12 Top 10 journals cited

\begin{tabular}{llc}
\hline Rank & Journal & Frequency \\
\hline 1 & Blood & 1,231 \\
2 & Bone Marrow Transpl & 1,100 \\
3 & Biol Blood Marrow Tr & 874 \\
4 & New Engl J Med & 779 \\
5 & Clin Infect Dis & 670 \\
6 & Transplantation & 648 \\
7 & J Infect Dis & 610 \\
8 & Brit J Haematol & 604 \\
9 & Lancet & 452 \\
10 & Transpl Infect Dis & 423 \\
\hline
\end{tabular}

Table 13 Top 10 journals for centrality

\begin{tabular}{llc}
\hline Rank & Journal & Centrality \\
\hline 1 & AIDS & 0.07 \\
2 & Ann Intern Med & 0.05 \\
3 & Am J Clin Pathol & 0.05 \\
4 & Am J Ophthalmol & 0.05 \\
5 & Nature & 0.04 \\
6 & Antimicrob Agents Ch & 0.04 \\
7 & J Gen Virol & 0.04 \\
8 & Am J Med & 0.04 \\
9 & Antivir Res & 0.04 \\
10 & JAMA-J Am Med Assoc & 0.04 \\
\hline
\end{tabular}

use, and concomitant Epstein-Barr virus infection during the transplant pretreatment regimen (12). All these risk factors are associated with defective immune surveillance of CMV. Further, the situation of CMV infection in children undergoing allogeneic hematopoietic stem-cell transplantation is more serious than adults with a higher prevalence (13). CMV infection after HSCT mainly manifests as respiratory symptoms and other nonspecific symptoms, which are easily overlooked. Therefore, when transplant patients have any new clinical symptoms, timely laboratory tests should be performed to confirm whether CMV infection has occurred. The most effective method for confirming CMV pneumonia is to use bronchoalveolar lavage fluid to detect CMV nucleic acid; if the test is 


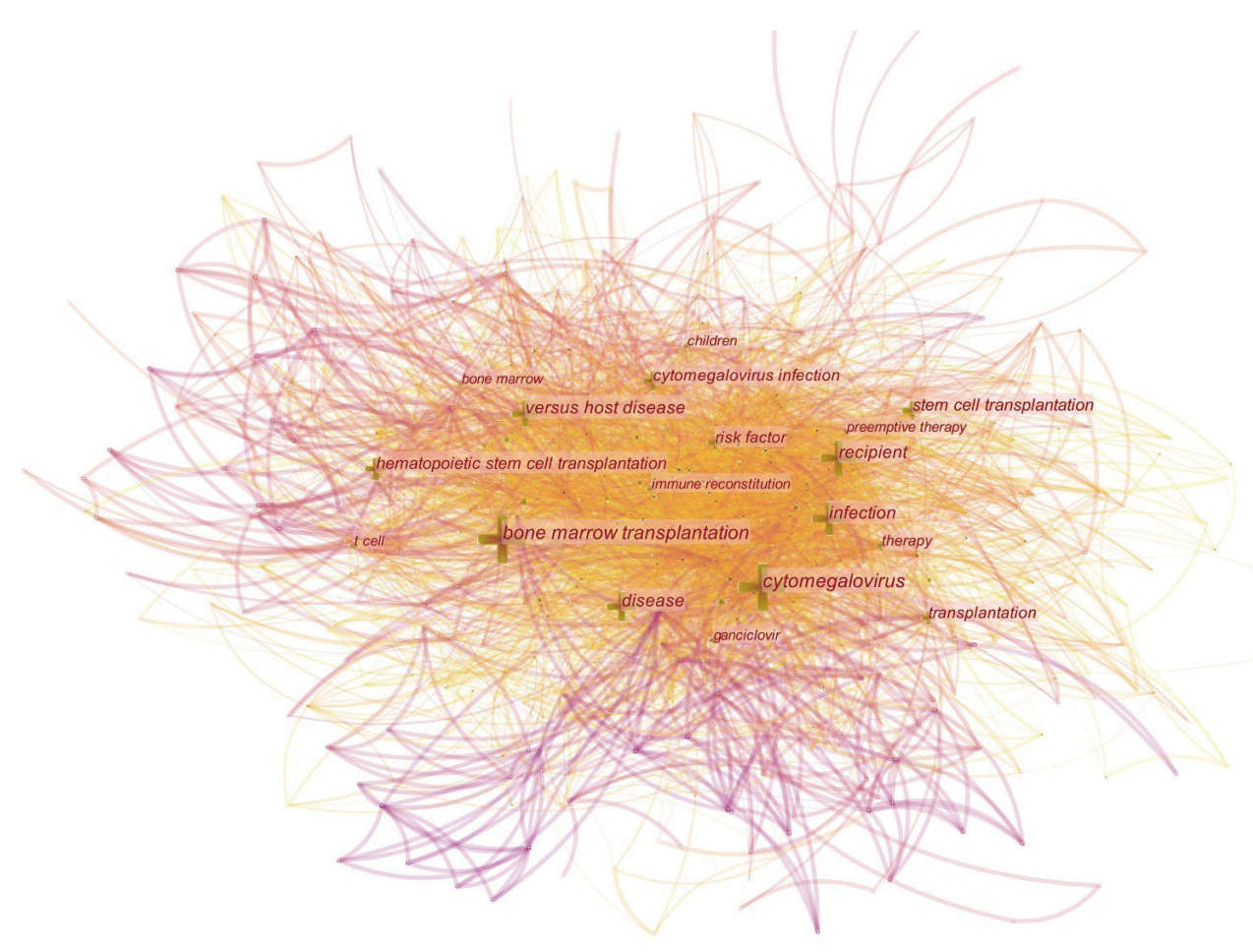

Figure 7 Visualization map of keyword cooccurrence.

Table 14 Top 10 keywords

\begin{tabular}{llc}
\hline Rank & Keyword & Frequency \\
\hline 1 & cytomegalovirus & 498 \\
2 & bone marrow transplantation & 458 \\
3 & recipient & 311 \\
4 & infection & 290 \\
5 & versus host disease & 279 \\
6 & disease & 259 \\
7 & stem cell transplantation & 203 \\
8 & hematopoietic stem cell transplantation & 201 \\
9 & risk factor & 163 \\
10 & cytomegalovirus infection & 157 \\
\hline
\end{tabular}

negative, CMV can generally be ruled out.

There are currently 2 strategies for the prevention of CMV infection after HSCT: universal prophylaxis and preemptive therapy. Due to the adverse effects of antiviral drugs, under strict CMV-DNA testing and immune function monitoring, preemptive treatment strategies are
Table 15 Top 10 keywords for centrality

\begin{tabular}{llc}
\hline Rank & Keyword & Centrality \\
\hline 1 & bone marrow transplantation & 0.30 \\
2 & hematopoietic stem cell & 0.15 \\
3 & transplantation & 0.10 \\
4 & cytomegalovirus & 0.09 \\
5 & versus host disease & 0.07 \\
6 & recipient & 0.06 \\
7 & infection & 0.06 \\
8 & blood & 0.05 \\
9 & polymerase chain reaction & 0.05 \\
10 & disease & 0.04 \\
\hline
\end{tabular}

often adopted (14). However, with the exception of a phase III letermovir clinical trial, preemptive treatment strategies have not been shown to reduce all-cause mortality in patients with CMV infection after HSCT (15). At present, most researchers believe that universal prevention strategies usually have more advantages than disadvantages for patients with a higher risk of CMV infection. In fact, in a 
Top 25 Keywords with the Strongest Citation Bursts

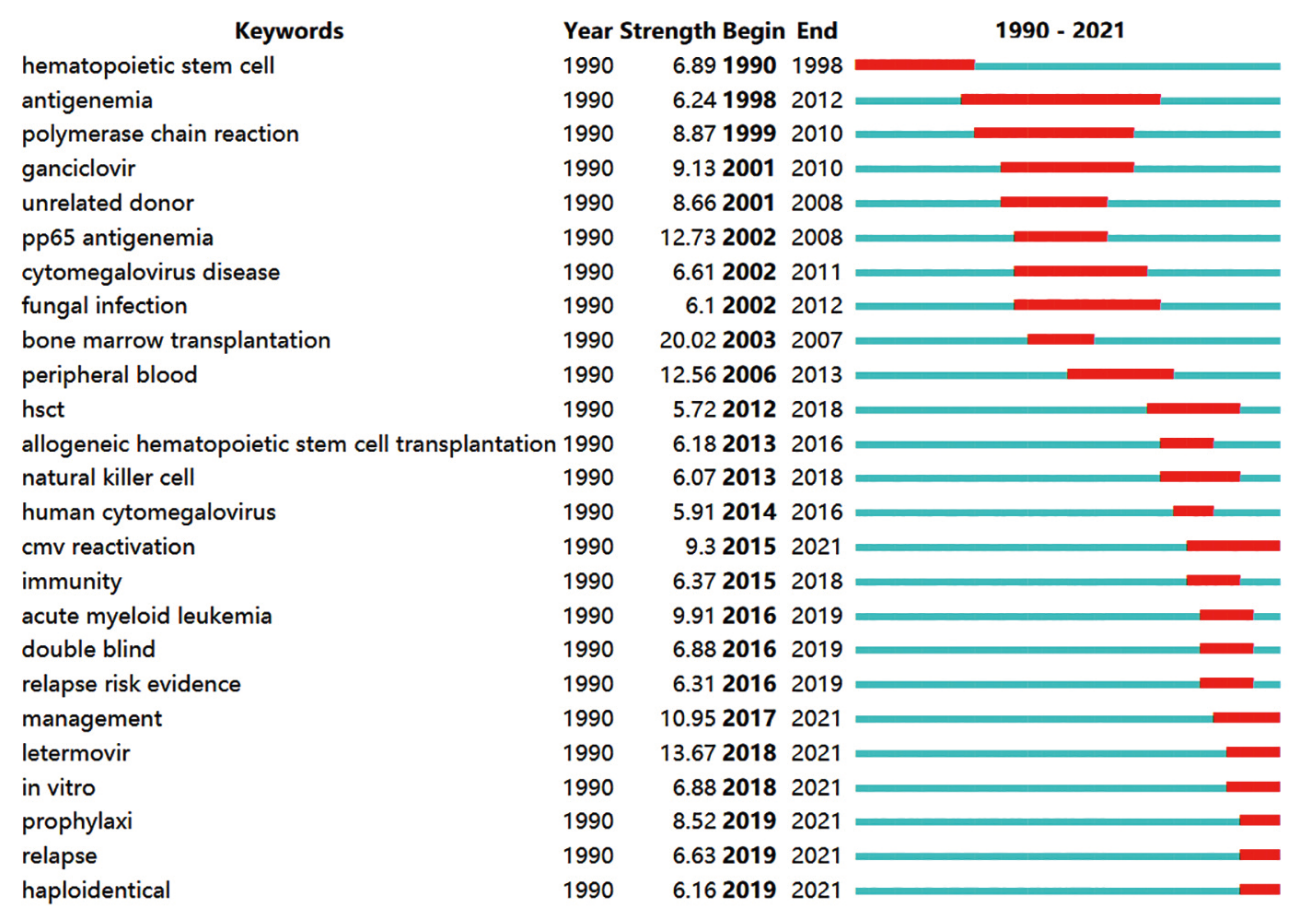

Figure 8 Top 25 keywords with the strongest citation bursts.

systematic review and meta-analysis, the authors found that there was no effective strategy for reducing the risk of blood transfusion-related CMV infection in high-risk patients (16). So, further research is needed to identify which patients might benefit from universal prevention strategies (17). Real-time PCR is the main method to detect CMV in this kind of patients and whole blood or plasma samples can both be used to detect CMV (14).

With respect to treatment, ganciclovir and valganciclovir are still used as first-line drugs. The most common adverse reaction is bone marrow suppression, with an incidence of $20-50 \%$. Long-term use is prone to drug resistance $(6,18,19)$. In recent years, there has been significant progress in the development of new anti-CMV drugs (20), including letermovir (15), maribavir (21), and brincidofovir (22). The results of a current phase III clinical trial are encouraging (20). In addition to antiviral therapy, immunoglobulin can also be considered (23). However, as there remains a lack of consensus regarding its effects, careful consideration is needed when using immunoglobulin. CMV-specific T cell infusion may provide a new option for the prevention and treatment of CMV infection after transplantation, but this therapy is limited by the donor's CMV serological status and the donor's own immune response to CMV infection $(24,25)$. Related studies are currently being carried out more frequently, with most research concentrated in the United States, Germany, and Italy, and there is more cooperation between countries and institutions, which is consistent with our research results. However, due to the large number of participating institutions and authors, cooperation between the main researchers in this field has been relatively scattered. More international and multicenter cooperation is needed in the future to advance research in this field.

This study had some limitations. Our analysis found that the authors were relatively unsystematic when using keywords. The 1,476 documents we used included a total of 337 keywords, and some of these had similar or identical meanings. This created obstacles for us in accurately analyzing the use of keywords. In future research, we hope to combine synonymous keywords through software calculations to more accurately reflect the focus of research in different periods.

\section{Acknowledgments}

Funding: None. 


\section{Footnote}

Conflicts of Interest: All authors have completed the ICMJE uniform disclosure form (available at https://dx.doi. org/10.21037/apm-21-2301). The authors have no conflicts of interest to declare.

Ethical Statement: The authors are accountable for all aspects of the work in ensuring that questions related to the accuracy or integrity of any part of the work are appropriately investigated and resolved.

Open Access Statement: This is an Open Access article distributed in accordance with the Creative Commons Attribution-NonCommercial-NoDerivs 4.0 International License (CC BY-NC-ND 4.0), which permits the noncommercial replication and distribution of the article with the strict proviso that no changes or edits are made and the original work is properly cited (including links to both the formal publication through the relevant DOI and the license). See: https://creativecommons.org/licenses/by-nc-nd/4.0/.

\section{References}

1. Dioverti MV, Razonable RR. Cytomegalovirus. Microbiol Spectr 2016;4.

2. Cho SY, Lee DG, Kim HJ. Cytomegalovirus Infections after Hematopoietic Stem Cell Transplantation: Current Status and Future Immunotherapy. Int J Mol Sci 2019;20:2666.

3. Fonseca Brito L, Brune W, Stahl FR. Cytomegalovirus (CMV) Pneumonitis: Cell Tropism, Inflammation, and Immunity. Int J Mol Sci 2019;20:3865.

4. Zhao M, Zhuo C, Li Q, Liu L. Cytomegalovirus (CMV) infection in HIV/AIDS patients and diagnostic values of CMV-DNA detection across different sample types. Ann Palliat Med 2020;9:2710-5.

5. Akahoshi Y, Kimura SI, Inamoto Y, et al. Effect of Cytomegalovirus Reactivation With or Without Acute Graft-Versus-Host Disease on the Risk of Nonrelapse Mortality. Clin Infect Dis 2021;73:e620-8.

6. Green ML, Leisenring W, Xie H, et al. Cytomegalovirus viral load and mortality after haemopoietic stem cell transplantation in the era of pre-emptive therapy: a retrospective cohort study. Lancet Haematol 2016;3:e119-27.

7. Zhou X, Jin N, Chen B. Human cytomegalovirus infection: A considerable issue following allogeneic hematopoietic stem cell transplantation. Oncol Lett 2021;21:318.

8. Lewison G. Preparation of bibliometrics papers. An Acad Bras Cienc 2020;92:e20201327.

9. Sugimoto CR, Ahn YY, Smith E, et al. Factors affecting sex-related reporting in medical research: a crossdisciplinary bibliometric analysis. Lancet 2019;393:550-9.

10. Styczynski J. Who Is the Patient at Risk of CMV Recurrence: A Review of the Current Scientific Evidence with a Focus on Hematopoietic Cell Transplantation. Infect Dis Ther 2018;7:1-16.

11. Ozdemir E, Saliba RM, Champlin RE, et al. Risk factors associated with late cytomegalovirus reactivation after allogeneic stem cell transplantation for hematological malignancies. Bone Marrow Transplant 2007;40:125-36.

12. Teira P, Battiwalla $M$, Ramanathan $M$, et al. Early cytomegalovirus reactivation remains associated with increased transplant-related mortality in the current era: a CIBMTR analysis. Blood 2016;127:2427-38.

13. Jaing TH, Chang TY, Chen SH, et al. Factors associated with cytomegalovirus infection in children undergoing allogeneic hematopoietic stem-cell transplantation. Medicine (Baltimore) 2019;98:e14172.

14. Ljungman P, de la Camara R, Robin C, et al. Guidelines for the management of cytomegalovirus infection in patients with haematological malignancies and after stem cell transplantation from the 2017 European Conference on Infections in Leukaemia (ECIL 7). Lancet Infect Dis 2019;19:e260-72.

15. Marty FM, Ljungman P, Chemaly RF, et al. Letermovir Prophylaxis for Cytomegalovirus in Hematopoietic-Cell Transplantation. N Engl J Med 2017;377:2433-44.

16. Mainou M, Alahdab F, Tobian AA, et al. Reducing the risk of transfusion-transmitted cytomegalovirus infection: a systematic review and meta-analysis. Transfusion 2016;56:1569-80.

17. Haidar G, Boeckh M, Singh N. Cytomegalovirus Infection in Solid Organ and Hematopoietic Cell Transplantation: State of the Evidence. J Infect Dis 2020;221:S23-31.

18. Yong MK, Gottlieb D, Lindsay J, et al. New advances in the management of cytomegalovirus in allogeneic haemopoietic stem cell transplantation. Intern Med J 2020;50:277-84.

19. Meesing A, Razonable RR. New Developments in the Management of Cytomegalovirus Infection After Transplantation. Drugs 2018;78:1085-103.

20. Frange P, Leruez-Ville M. Maribavir, brincidofovir and letermovir: Efficacy and safety of new antiviral drugs for treating cytomegalovirus infections. Med Mal Infect 
2018;48:495-502.

21. Maertens J, Cordonnier C, Jaksch P, et al. Maribavir for Preemptive Treatment of Cytomegalovirus Reactivation. N Engl J Med 2019;381:1136-47.

22. Marty FM, Winston DJ, Chemaly RF, et al. A Randomized, Double-Blind, Placebo-Controlled Phase 3 Trial of Oral Brincidofovir for Cytomegalovirus Prophylaxis in Allogeneic Hematopoietic Cell Transplantation. Biol Blood Marrow Transplant 2019;25:369-81.

23. Blázquez-Gamero D, Galindo Izquierdo A, Del Rosal T, et al. Prevention and treatment of fetal cytomegalovirus infection with cytomegalovirus hyperimmune globulin:

Cite this article as: Chen $\mathrm{P}, \mathrm{Du} \mathrm{Z}$, Qiu S, Wang $\mathrm{H}$, Zhang J, Liu D. Current research status of cytomegalovirus infection after hematopoietic stem cell transplantation: a bibliometric analysis. Ann Palliat Med 2021;10(9):9614-9626. doi: 10.21037/ apm-21-2301 a multicenter study in Madrid. J Matern Fetal Neonatal Med 2019;32:617-25.

24. Ottaviano G, Chiesa R, Feuchtinger T, et al. Adoptive T Cell Therapy Strategies for Viral Infections in Patients Receiving Haematopoietic Stem Cell Transplantation. Cells 2019;8:47.

25. Simmons HZ, Bazzell AF, Dains JE. Adverse Effects of Virus-Specific T-Cell Therapy: An Integrative Review. J Adv Pract Oncol 2019;10:120-31.

(English Language Editor: A. Muijlwijk) 